\title{
KINERJA KARYAWAN DITINJAU DARI KEPEMIMPINAN, LINGKUNGAN KERJA, DAN DISIPLIN KERJA PADA SHOWROOM MUHARI MOTOR 651 KARANGANYAR
}

\author{
Fiya Mila Fatmawati, Sri Hartono, Istiatin \\ Prodi Manajemen Fakultas Ekonomi, Universitas Islam Batik Surakarta \\ e-mail:millafiya@gmail.com
}

\begin{abstract}
This study aims to support leadership, work environment and work discipline on the performance of employees of the Muhari Motor 651 Karanganyar Showroom. This research uses quantitative descriptive. The population in this study were all 116 participants and the sample used was 90 respondents by distributing questionnaires. Data were analyzed using SPSS version 21,hypothesis testing using multiple linear regression analysis. With the approved questionnaire questions declared valid and reliable. In the classical research assumptions test produces normal data, there is no multicollinearity and heteroscedasticity does not occur. From the results of the F test stated that the variables of leadership, work environment and work coordination determine simultaneous and significant impact on employee performance at the Muhari Motor 651 Karanganyar Showroom with a Fcount of 126.690> Ftable 3.101 and a significant value of $0.000<0.05$. T test results with leadership variables (X1) have a positive and significant effect on employee performance with the results of tcount 4.701> ttable 1.988 significant value $0.000<0.05$. Except the Work Environment variable is not significant on employee performance with a value of -0.947 <ttable 1.988 with a significant value of 0.346> 0.05. Variable positive and significant work discipline on employee performance with a tcount of 6.137> t table 1.988 and a significant value of $0.000<0.05$.
\end{abstract}

Keywords: Performance, leadership, work environment, work discipline

\section{PENDAHULUAN}

Pada persaingan dunia usaha yang semakin berkembang dan kuat, perusahaan menginginkan kinerja karyawan terus meningkat. Kinerja sebagai bentuk perwujudan perilaku seorang karyawan sesuai kemampuan yang dimilikinya. Murdiyanto (2012) tanpa adanya kinerja yang baik maka perusahaan tidak akan mencapai tujuannya. Salah satu langkah untuk mempertahankan atau meningkatkan kinerja, maka perusahaan harus memperbaiki sistem kerja pada karyawan untuk menghasilkan kinerja yang lebih baik.

Salah satu faktor yang dapat meningkatkan kinerja karyawan yaitu kepemimpinan. Dimana kepemimpinan mempunyai sifat perilaku untuk memberi motivasi kepada bawahannya. Keberhasilan seorang pemimpin tergantung dari kompetensi yang dimiliki dalam menciptakan semanagat kerja pada karyawan (Tampi 2014). Saerang, Kawet dan Watung (2016) menyebutkan bahwa lingkungan kerja memiliki pengruh positif terhadap kinerja karyawan. Sehingga perusahaan harus meningkatkan kebersihan lingkungan kerja, melengkapi fasilitas-fasilitas yang kurang memadai di perusahaan dan dapat membangun hubungan antar karyawan yang lebih baik, maka dengan begitu kinerja akan meningkat.

Selain faktor kepemimpinan dan lingkungan kerja, kinerja karyawan juga dipengaruhi oleh adanya disiplin kerja. Disiplin kerja memiliki sikap sadar dan 
kesediaan untuk mentaati aturan-aturan pada perusahaan. Dimana seseorang yang mempunyai kedisiplinan, maka cenderung akan bekerja sesuai peraturan dan kewajiban yang sudah menjadi tugasnya. Sehingga pekerjaan akan berjalan dengan lancar dan perusahaan akan mengalami peningkatan yang lebih baik. Menurut Sari (2014) menyatakan disiplin kerja berpengaruh dan tidak signifikan terhadap kinerja karyawan.

Showroom Muhari Motor 651 Karanganyar merupakan salah satu perusahaan yang bergerak dibidang jual - beli sepeda motor bekas tidak hanya motor bekas saja melainkan juga melayani jual - beli sepeda motor baru. Showroom Muhari Motor 651 Karanganyar yang beralamat di Badran Baru 08/08 Papahan, Tasikmadu Karanganyar. Dengan jumlah karyawan sebanyak 116 karyawan. Dengan tingginya tingkat persaingan dan minat konsmen dengan adanya jual - beli motor bekas, maka pemilik Showroom mulai membuka anak cabang dengan sampai sekarang ini sebanyak 17 anak cabang yang berada di Sekresidenan Surakarta.

Dari uraian diatas peneliti mendapatkan hak untuk melakukan penelitian dengan judul Kinerja karyawan ditinjau dari kepemiminan, lingkungan kerja, dan disiplin kerja pada Showroom Muhari Motor 651 Karanganyar.

\section{LANDASAN TEORI}

\section{Kinerja Karyawan}

Handoko (2011: 135) menyatakan kinerja (perfomance) sebagai proses perusahan dalam mengevaluasi atau menilai prestasi kerja karyawan. Kemampuan kinerja seseorang untuk menujukan prestasi kerjanya dengan cara menyelesaikan tugasnya dengan baik dan tanggung jawabnya. Menurut Sari (2014) kinerja merupakan suatu perilaku nyata yang akan menghasilkan kinerjanya sesuai kemampuan yang dimiliki. Kemampuan kinerja seseorang untuk menujukan prestasi kerjanya dengan cara menyelesaikan tugasnya dengan baik dan tanggung jawabnya. Menurut (Sedarmayanti 2017: 286) indikator-indikator kinerja karyawan diantaranya: kualitas, kuantitas, ketepatan waktu, kemampuan bekerjasama dan kemandirian.

\section{Kepemimpinan}

Istiatin dan Samsi (2019:2) menjelaskan bahwa kepemimpinan adalah kemampuan lebih yang dimiliki seseorang untuk mempengaruhi orang-orang yang ada di lingkungannya sehingga mereka bersedia mencapai tujuan yang dinginkan. Menurut Edison (2016:89) pemimpin adalah seseorang yang memiliki bawahaan atau pengikut untuk mencapai suatu tujuan dan keberhasilannya sangat dipengaruhi oleh kepemimpinan yang dimilikinya. Menurut Rivai dan Mulyadi (2012: 253) kepemimpinan memiliki beberapa indikator yaitu: Kekuasaan atau pengaruh, hubungan kerjasama, pengambilan keputusan secara musyawarah, usaha pencapaian tujuan dan memberi bimbingan dan pelatihan dalam pengambilan keputusan.

\section{Lingkungan Kerja}

Sedarmayanti (2017: 343) menyatakan bahwa suatu tempat yang terdapat sejumlah kelompok dimana di dalamnya terdapat beberapa fasilitas pedukung untuk mencapai tujuan perusahaan sesuai visi dan misi perusahaan. Yang dapat meningkatkan kinerja karyawan salah satunya harus memperhatikan kondisi lingkungan kerja. Ketika seorang karyawan bekerja mendapatkan perlindungan dan 
penjaminan rasa aman dalam bekerja, maka karyawan akan cenderung memiliki hasil kerja yang lebih baik. Lingkungan kerja adalah kehidupan fisik dalam perusahaan yang berpengaruh terhadap pekerja dalam melaksanakan tugasnya (Hamid, 2014: 48 - 49). Kehidupan manusia tidak terlepas dari berbagai keadaan lingkungan sekitarnya, antara manusia dan lingkungan terdapat hubugan yang sangat erat. Adanya lingkungan kerja yang nyaman dan aman, maka kinerja karyawan akan lebih meningkat. Sedarmayanti (2017: 343) indikator yang dimiliki sebagai berikut: fasilitas, tingkat keamanan, hubungan antar karyawan dan komunikasi yang baik.

\section{Disiplin Kerja}

Disiplin kerja adalah kesadaran dan kesediaan seseorang untuk mentaati semua peraturan yang ada diperusahaan. Kesadaran merupakan perilaku seseorang yang mampu mentaati semua peraturan dan sadar akan tugas dan tanggung jawabnya. Jadi, karyawan akan mematuhi atau akan mengerjakan semua tugasnya dengan baik, bukan atas dasar paksaan. Sedangkan kesediaan merupakan suatu sikap atau tingkah laku dan perbuatan seseorang sesuai dengan peraturan perusahan, baik yang tertulis maupun tidak tertulis (Hasibuan, 2019 : 193). Disiplin harus ditegakkan dalam suatu perusahaan. Disiplin berperan sangat penting dalam pertumbuhan perusahaan untuk memotivasi karyawan agar dapat mendisiplinkan diri dalam melaksanakan pekerjaan secara individu maupun kelompok. Samsudin (2012: 145) menyatakan disiplin kerja ialah sikap yang mampu menghormati, menghargai dan taat terhadap peraturan- peraturan yang ditetapkan perusahaan dan wewenang yang diberikan kepadanya. Tanpa dukungan disiplin karyawan yang baik, sulit bagi perusahaan untuk mewujudkan tujuannya (Setiawan, 2013). Disiplin kerja juga memilki suatu sikap, perilaku dan perbuatan yang sesuai dengan peraturan yang ada dari perusahaan, baik secara tertulis maupun tidak tertulis. Jadi, kedisiplinan merupakan kunci keberhasilan suatu perusahaan dalam mencapai tujuannya. Indikator - indikator disiplin kerja adalah ketepatan waktu dalam bekerja, tingkat kewaspadaan karyawan, rasa tanggungjawab, ketaatan pada aturan kerja dan etika dalam bekerja.

\section{Kerangka Pemikiran}

Dalam penelitian ini kerangka pemikirannya sebagai berikut:

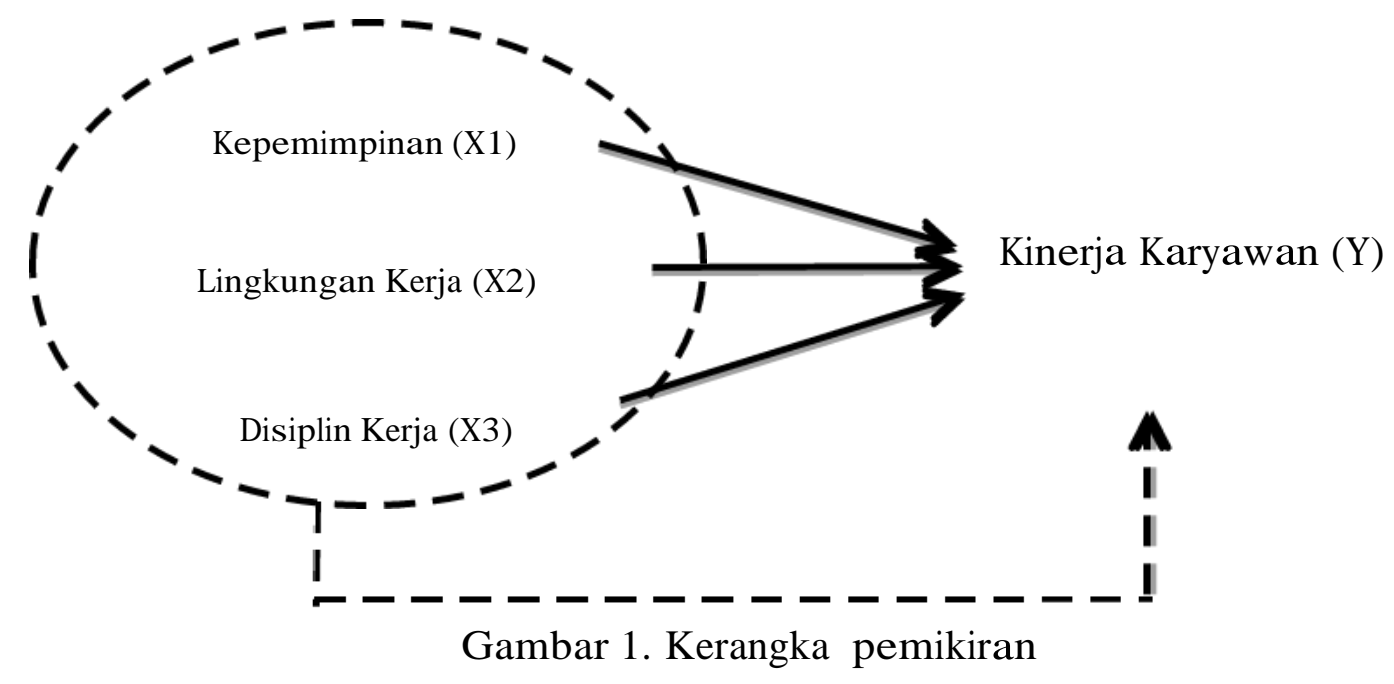




\section{Hipotesis}

Berdasarkan teori dan kerangka pemikiran maka dapat disimpulkan bahwa:

a. H1 : Kepemimpinan, lingkungan kerja dan disiplin kerja berpengaruh simultan dan signifikan terhadap kinerja karyawan

b. H2 : Kepemimpinan berpengaruh positif dan signifikan terhadap kinerja karyawan

c. H3 : Lingkungan kerja berpengaruh positif dan signifikan terhadap kinerja karyawan

d. H4 : Disiplin kerja berpengaruh positif dan signfikan terhadap kinerja karyawan

\section{METODOLOGI PENELITIAN}

Penelitian ini adalah deskriptif kuantitatif yang dilakukan di Showroom Muhari Motor 651 Karanganyar yang dilaksanakan bulan Oktober 2019 sampai dengan Januari 2020. Populasi dipeneliian ini adalah karyawan Showroom Muhari Motor 651 Karyawan berjumlah 116 orang. Sampel berjumlah 90 orang dengan teknik sampling random sampling. Untuk mendapatkan informasi peneliti melakukan observasi, dokumentasi, kuesioner, dan wawancara. Teknik analisis dipenelitian ini menggunakan SPSS 21 dalam menganalisis data.

\section{HASIL DAN PEMBAHASAN}

a. Analisa Data

1) Uji Asumsi Klasik

\section{Uji Normalitas}

Didalam penelitian ini uji normalitas menggunakan kolmogorov- smirnov dapat diketahui dengan nilai 1,035. Dengan nilai asymp.sig sebesar 0,235>0,05. Hal inimenunjukkan bahwa model regresi uji normalitas berdistribusi normal.

\section{Uji Multikolinieritas}

Uji multikolineritas yang dibahas dipenelitian ini menggunakan VIF Dapat diketahui bahwa variabel kepemimpinan memiliki nilai tolerance 0,219 dengan nilai VIF 4,560. Variabel lingkungan kerja memiliki nilai tolerance 0,193 dengan nilai VIF 5,178. Variabel disiplin kerja memiliki nilai tolerance 0,247 dengan nilai VIF 4,050. Dengan demikian dapat diketahui bahwa nilai tolerance lebih besar 0,10 dan nilai VIF lebih kecil dari 10. Sehingga dapat disimpulkan bahwa persamaan regresi tidak terjadi multikolinieritas.

\section{Uji Heteroskedastisitas}

Uji heterokedastisitas yang dibahas dipenelitian ini memakai uji glesjer. Variabel kepemimpinan memiliki nilai 0,297>0,05. Variabel lingkungan kerja memiliki nilai $0,589>0,05$. Variabel disiplin kerja memiliki nilai tolerance 0,968>0,05. Dengan demikian dapat diketahui bahwa nilai variabel $>0,05$. Sehingga dapat disimpulkan bahwa persamaan regresi tidak terjadi heteroskedastisitas.

\section{2) Uji Regresi Liniear Berganda}

Hasil analisa data menggunakan program SPSS 21 hasil uji regresi linier berganda dibawah ini:

$$
\mathrm{Y}=1,801+0,443 \mathrm{X} 1-0,114 \mathrm{X} 2+0,530 \mathrm{X} 3+\mathrm{e}
$$


Nilai konstanta untuk persamaan regresi dengan nilai 1,801 artinya apabila variabel independent yaitu kepemimpinan (X1), lingkungan kerja (X2) dan disiplin kerja (X3) nilainya sama dengan 0 , maka variabel kinerja karyawan nilainya masih tetapa 1,801 .

Koefisien regresi pada variabel kepemimpinan memiliki arah positif dengan nilai 0,443. Apabila terjadinya peningkatan variabel kepemimpinan sebesar 1 satuan, maka variabel kepemimpinan akan mengalami peningkatan sebesar 0,443 dengan asumsi variabel lingkungan kerja dan disiplin kerja tetap

Koefisien regresi pada variabel lingkungan kerja memiliki arah negatif dengan nilai - 0,114. Apabila terjadinya peningkatan variabel lingkungan kerja sebesar 1 satuan, maka variabel lingkungan kerja akan mengalami penurunan sebesar 0,114 dengan asumsi variabel kepemimpinan dan disiplin kerja tetap

Koefisien regresi pada variabel disiplin kerja memiliki arah positif dengan nilai 0,530. Apabila terjadinya peningkatan variabel disiplin kerja sebesar 1 satuan, maka variabel disiplin kerja akan mengalami peningkatan sebesar 0,530 dengan asumsi variabel kepemimpinan dan lingkungan kerja tetap.

\section{3) Uji Hipotesis}

Uji F

Dari olah data menggunakan SPSS 21 diperoleh Nilai signifikan Fhitung sebesar 0,000 dimana nilai tersebut kurang dari 0,05 dan Fhitung 126,690 > Ftabel 3,101. Maka dapat disimpulkan bahwa H1 diterima yang artinya variabel kepemimpinan, lingkungan kerja dan disiplin kerja berpengaruh secara simultan dan signifikan pada kinerja karyawan Showroom Muhari Motor 651 Karanganyar.

Variabel Kepemimpinan menunjukan bahwa nilai thitung 4,701 > ttabel 1,988 dengan nilai signifikan $0,000<0,05$. Disimpulkan bahwa variabel kepemimpinan berpengaruh positif dan signifikan terhadap kinerja karyawan pada Showroom Muhari Motor 651 Karanganyar sehingga $\mathrm{H} 2$ diterima

Variabel Lingkungan Kerja menunjukan bahwa nilai thitung $-0,947<$ ttabel 1,988 dengan nilai signifikan 0,346>0,05. Disimpulkan bahwa variabel lingkungan kerja berpengaruh negatif dan tidak signifikan terhadap kinerja karyawan pada Showroom Muhari Motor 651 Karanganyar sehingga H3 ditolak

Variabel Disiplin Kerja menunjukan bahwa nilai thitung 6,137> ttabel 1,988 dengan nilai signifikan $0,000<0,05$. Disimpulkan bahwa variabel disiplin kerja berpengaruh positif dan signifikan terhadap kinerja karyawan pada Showroom Muhari Motor 651 Karanganyar sehingga H4 diterima

\section{Uji Koefisien Determinan $\left(\mathbf{R}^{2}\right)$}

Hasil analisa data menggunakan program SPSS 21 diperoleh nilai $\mathrm{R}^{2}$ adalah 80,9\%. Nilai ini membuktikan kinerja karyawan Showroom Muhari Motor 651 Karanganyar dijelaskan oleh varaiabel kepemimpinan, lingkungan kerja dan disiplin kerja sebesar $80,9 \%$, sedangkan sisanya 19,1\% dipengaruhi oleh variabel lainnya yang tidak diteliti. 


\section{b. Pembahasan}

1) Kepemimpinan, Lingkungan Kerja dan Disiplin Kerja terhadap kinerja karyawan Showroom Muhari Motor 651 Karanganyar.

Berdasarkan hasil uji SPSS menunjukkan bahwa nilai Fhitung (126,690) > Ftabel $(3,101)$ dan nilai signifikan $(0,000<0,05)$, sehingga $\mathrm{H} 0$ ditolak dan Ha diterima yang berarti variabel kepemimpinan, lingkungan kerja dan disiplin kerja secara simultan dan signifikan berpengaruh terhadap kinerja. Dengan demikian $\mathrm{H} 1$ dalam penelitian ini terbukti kebenarannya.

Hasil penelitian ini menujukkan bahwa variabel kepemimpnan, lingkungan kerja dan disiplin kerja merupakan faktor - faktor yang dapat berpengaruh terhadap kinerja karyawan pada Showroom Muhari Motor 651 Karanganyar.

2) Variabel Kepemimpinan terhadap kinerja karyawaan pada Showroom Muhari Motor 651 Karanganyar.

Berdasarkan hasil uji SPSS variabel kepempinan menunjukkan bahwa nilai thitung $(4,701)>$ ttabel $(1,988)$ dan nilai signifikan $(0,000<0,05)$, maka $\mathrm{H} 0$ ditolak dan $\mathrm{Ha}$ diterima yang berarti variabel kepemimpinan berpengaruh positif dan signifikan terhadap kinerja karyawa. Sehingga $\mathrm{H} 2$ dalam penelitian ini terbukti kebenarannya.

Sejalan dengan penelitian yang dilakukan Istiqomah, Parwoto dan Hartono (2017) juga berpendapat bahwa kepemimpinan berpengaruh signifikan terhadap kinerja karyawan. Kemudian penelitian yang dilakukan Irjanto dan Setiawan (2016) menyatakan kepemimpinan berpengaruh signifikan terhadap kinerja karyawan. Jika semakin bagus nilai kepemimpinan yang diterapkan diperusahaan maka kinerja karyawan akan semakin meningkat.

Dapat dikatakan bahwa kepemimpinan di Showroom Muhari Motor 651 Karanganyar sudah berjalan dengan baik. Dimana seorang pemimpin mempunyai sikap kewibawaan yang baik terhadap karyawan dan dapat memberikan nilai positif kepada karyawanntya. Dilihat dari sikap perilaku seorang pemimpin yang selalu memberikan motivasi dan dukungan semangat kerja kepada karyawannya.

3) Variabel Lingkungan Kerja terhadap kinerja karyawaan pada Showroom Muhari Motor 651 Karanganyar.

Berdasarkan hasil uji SPSS variabel lingkungan kerja menunjukkan nilai thitung $(-0,947)<$ ttabel $(1,988)$ dan nilai signifikan $(0,346>0,05)$, maka $\mathrm{H} 0$ diterima dan $\mathrm{Ha}$ ditolak yang berarti variabel lingkungan kerja berpengaruh negatif dan tidak signifikan terhadp kinerja karyawan. Dengan demikian H3 dalam penelitian ini tidak terbukti kebenarannya.

Hasil tersebut tidak sesuai dengan penelitian Saerang, Kawet dan Watung (2016) lingkungan kerja berpengaruh signifikan terhadap kinerja karyawan. Penelitian ini juga tidak didukung dari peneliti Prasetyo, Rahmawati dan Swasto (2014) bahwa lingkungan kerja berpengaruh signifikan terhadap kinerja karyawan. Maka perusahaan dituntut untuk menciptakan lingkungan kerja yang lebih kondusif sehingga karyawan akan merasa nyaman dalam bekerja.

Dapat dikatakan bahwa variabel lingkungan kerja yang ada di Showroom 
Muhari Motor 651 Karanganyar dinyatakan kurang baik. Dilihat dari kondisi lingkungan yang kurang kondusif dan hubungan antar karyawan yang masih rendah, maka akan terjadinya penurunan pada kinerja karyawan. Dari hasil responden ketika wawancara banyak karyawan yang merasa kurang nyaman dalam hal keamanan bekerja. Adanya hubungan antar karyawan yang kurang baik, maka dapat menyebabkan kinerja karyawan menurun. Hubungan komunikasi antar rekan kerja maupun pimpinan, maka perlu ditingkatkan agar tidak terjadinya miskomunikasi antar pekerja lain. Maka manajer perlu meningkatkan fasilitas dan memperbaiki hubungan dengan karyawan yang lainnya. Dengan meningkatkan sistem kerja perusahaan maka karyawan merasa dapat perlindungan dalam hal pekerjaan. Jadi karyawan dapat memaksimalkan pekerjaannya.

4) Variabel Disiplin Kerja terhadap kinerja karyawaan pada Showroom Muhari Motor 651 Karanganyar.

Berdasarkan hasil uji SPSS variabel disiplin kerja menunjukkan nilai thitung $(6,137)>$ ttabel $(1,988)$ dan nilai signifikan $(0,000<0,05)$, maka $\mathrm{H} 0$ ditolak dan $\mathrm{Ha}$ diterima yang berarti variabel disiplin kerja berpengaruh positif dan signifikan terhadp kinerja karyawan pada Showroom Muhari Motor 651 Karanganyar. Dengan demikian H4 dalam penelitian ini terbukti kebenarannya.

Hasil ini tidak sesuai dengan penelitian Sari (2014) yang menyatakan disiplin kerja berpengaruh dan tidak signifikan terhadap kinerja karyawan. Penelitian ini juga tidak sesuai dengan penelitian Setiawan (2013) yang membuktikan disiplin kerja berpengaruh tidak secara simultan dan parsial kepada kinerja karyawan.

Dapat diketahui bahwa variabel disiplin kerja sudah berjalan dengan baik. Dimana karyawan memiliki sikap sadar atau kesediaan dalam bekerja dan dapat menjalankan aturan - aturan yang ada diperusahaan. Disiplin Kerja pada Showroom Muhari Motor 651 Karanganyar memberikan niali positif bagi perusahaan. Tanpa adanya dukungan disiplin karyawan yang baik, sulit bagi perusahaan untuk mewujudkan tujuan - tujuannya. Dengan disiplin yang baik juga dapat mencerminkan rasa tanggung jawab pada diri sendiri tehadap tugas - tugas yang diberikan kepadanya baik secara individu maupun kelompok. Semakin tinggi tingkat disiplin karyawan maka semakin baik pula untuk meningkatkan kinerja perusahaan.

\section{KESIMPULAN DAN SARAN Kesimpulan}

Berdasarkan hasil penelitian dan pembahasan, maka kesimpulan yang dapat diambil dalam penelitian ini adalah:

1) Hasil uji $F$ menunjukkan bahwa variabel kepemimpinan, lingkungan kerja dan disiplin kerja berpengaruh secara simultan dan signifikan terhadap Kinerja Karyawan pada Showroom Muhari Motor 651 Karanganyar.

2) Berdasarkan hasil uji t menunjukkan:

a. Variabel Kepemimpinan berpengaruh positif dan signifikan terhadap Kinerja Karyawan pada Showroom Muhari Motor 651 Karanganyar.

b. Variabel Lingkungan Kerja berpengaruh negatif dan tidak signifikan 
terhadap Kinerja Karyawan pada Showroom Muhari Motor 651 Karanganyar.

c. Variabel Disipin Kerja berpengaruh positif dan signifikan terhadap Kinerja Karyawan pada Showroom Muhari Motor 651 Karanganyar.

3) Berdasarkan hasil regresi linier berganda maka, variabel disiplin kerja berpengruh terhadap kinerja karyawan pada Showroom Muhari Motor 651 Karanganyar dengan nilai uji sebesar 0,530. Karena karyawan memiliki rasa tanggungjawab pada perusahaan dan diri sendiri.

4) Dari hasil uji koefisien determinasi $\left(\mathrm{R}^{2}\right)$ dengan nilai $0,809 \%$ Hal ini menujukkan bahwa variabel kinerja karyawan dijelaskanoleh variabel kepemimpinan, lingkungan kerja dan disiplin kerja sebesar 80,9\%, sedangkan sisanya sebesar $19,1 \%$ dipengaruhi oleh variabel lainnya yang tidak diteliti.

\section{Saran}

Berdasarkan hasil kesimpulan dan keterbatasan penelitian diatas maka ada beberapa saran yang direkomendasikan kepada penelitian selanjutnya antara lain:

1) Sebaiknya pihak perusahaan harus meningkatkan lagi dari sikap kepemimpinannya. Karena masih banyak yang harus diperbaiki dalam perusahaan. Dan masih banyak yang dilakukan pemimpin untuk ikut serta dalam keterlibatan membimbing karyawan untuk menyelesaikan tugasnya.

2) Seharusnya pihak manajer harus memperhatikan kondisi-kondisi yang ada di lingkungan kerja sekitar. Masih banyak yang harus diperbaiki dan ditingkatkan lagi. Seperti melengkapi fasilitas-fasilitas yang kurang memadai, membangun hubungan antar karyawan yang lebih baik lagi. Jadi dengan kelengkapan tersebut pekerja akan lebih merasa nyaman dalam bekerja.

3) Diharapkan perusahaan senantiasa memperhatikan kinerja karyawannya baik dari kondisi lingkungan kerja, insentif, memberi reward atau pujian atas keberhasilannya dalam menyelesikan pekerjaan. Agar karyawan merasa lebih semangat dan bertanggungjawab dalam bekerja.

4) Pada penelitian selanjutnya diharapkan untuk menambahkan factor-faktor lain yang akan diteliti misalnya faktor kepuasan kerja, motivasi, produktivitas kerja dan lain - lain, sehingga hasil penelitian selanjutnya bisa membantu baik bagi penelitian maupun perusahaan. 


\section{DAFTAR PUSTAKA}

Edison, Emron dkk. (2016). Manajemen Sumber Daya Manusia. Bandung: CV. Alfabeta

Hamid Sanusi. (2014). Manajemen Sumber Daya Manusia Lanjutan. Yogyakarta: Deepublish

Handoko, T.H. (2011). Manajemen Personalia dan Sumberdaya Manusia.Yogyakarta: BPFE

Hasibuan, Malayu S.P. (2019). Manajemen Sumber Daya Manusia. Cetakan Ketujuh Belas. Jakarta: Bumi Aksara

Istiatin dan Samsi. (2019). Kepemimpinan. Surakarta: UNIBA

Istiqomah, Parwoto., dan Hartono, S. (2017). Pengaruh kompensasi, kepemimpinan, dan stress kerja terhadap kinerja karyawan PT PLN (PERSERO) area Surakarta. Jurnal Ekonomi dan Kewirausahaan 17(2): 353-361.

Murdiyanto, A. (2012). Analisis Pengaruh Motivasi dan Lingkungan Kerja terhadap Kinerja Karyawan Motor Hepy Cabang Jawa Tengah. Tema 9(1): 12 - 28.

Prasetya, A., Rahmawati, N.P., dan Swasto, B. (2014). Pengaruh lingkungan kerja terhadap kinerja karyawan (Studi pada karyawan kantor pelayanan pajak Pratama Malang Utara). Jurnal Administrasi Bisnis (JAB) 8(2): 1-9.

Saerang, L.S., Watung, R., dan Kawet, L. (2016). Pengaruh Lingkungan Kerja, Motivasi, Pelatihan, dan Kompensasi terhadap Kinerja Pegawai (Studi pada Dinas Pemuda dan Olahraga Kota Tomohon). Jurnal EMBA 4(2): 828 - 837.

Samsudin H. Sadeli. (2012). Manajemen Sumber Daya Manusia. Bandung: Pustaka Setia

Sari, Y.K. (2014). Pengaruh kepemimpinan, motivasi dan disiplin kerja terhadap kinerja karyawan pada PT. Patra Komala di Dumai. Jurnal Tepak Manajemen Bisnis 6(2): $119-127$.

Sedarmayanti. (2017). Manajemen Sumber Daya Manusia, Bandung: Refika Aditama

Kinerja Karyawan pada Rumah Sakit Umum Daerah Kanjuruhan Malang. Jurnal Ilmu Manajemen 1(4): 1245 - 1253.

Setiawan, H., dan Irjanto, B. (2016). Pengaruh Gaya Kepemimpinan dan Motivasi terhadap Kinerja Karyawan pada Industri UMKM di Wilayah D.I. Yogyakarta. Jurnal MAKSIPRENEUR 5(2): $15-26$.

Tampi, B. J. (2014). Pengaruh gaya kepemimpinan dan Motivasi terhadap Kinerja Karyawan pada PT. Bank Negara Indonesia, tbk (Regional Sales Manado). Journal "Acta Diuma” 3(4): $1-20$. 